\title{
Mechanism of Hypercalciuria in Genetic Hypercalciuric Rats Inherited Defect in Intestinal Calcium Transport
}

\author{
David A. Bushinsky* and Murray J. Favus ${ }^{\ddagger}$ \\ ${ }^{*}$ Nephrology and ${ }^{\ddagger}$ Endocrinology Sections, Department of Medicine, Pritzker School of Medicine, \\ The University of Chicago, Chicago, Illinois 60637
}

\begin{abstract}
Excessive urine calcium excretion in patients with idiopathic hypercalciuria may involve a primary increase in intestinal calcium absorption, overproduction of 1,25-dihydroxyvitamin $D_{3}$ or a defect in renal tubular calcium reabsorption. To determine the mechanism of hypercalciuria in an animal model, hypercalciuria was selected for in rats and the most hypercalciuric animals inbred. Animals from the fourth generation were utilized to study mineral balance and intestinal transport in relation to levels of serum $1,25(\mathrm{OH})_{2} \mathrm{D}_{3}$.

Both urine calcium excretion and net intestinal calcium absorption were greater in hypercalciuric males (HM) than in normocalciuric males (NM) and in hypercalciuric females (HF) than in normocalciuric females (NF). However, serum $1,25(\mathrm{OH})_{2} \mathrm{D}_{3}$ was lower in $\mathrm{HM}$ than in $\mathrm{NM}$ and not different in HF than in NF. Net calcium balance was more positive in HM than in NM and in HF than in NF. In vitro duodenal calcium net flux was correlated with serum $1,25(\mathrm{OH})_{2} \mathrm{D}_{3}$ in HM and HF and in NM and NF. However, with increasing serum $1,25(\mathrm{OH})_{2} \mathrm{D}_{3}$ there was greater calcium net flux in hypercalciuric rats than in normocalciuric controls.

Hypercalciuria in this colony of hypercalciuric rats is due to a primary intestinal overabsorption of dietary calcium and not an overproduction of $1,25(\mathrm{OH})_{2} \mathrm{D}_{3}$ or a defect in the renal tubular reabsorption of calcium.
\end{abstract}

\section{Introduction}

Hypercalciuria is common in patients with calcium oxalate nephrolithiasis and contributes to urine calcium oxalate supersaturation $(1,2)$. Intestinal calcium absorption is increased in almost all patients with excessive urine calcium excretion of genetic origin (3-16), so called idiopathic hypercalciuria. The relationship between intestinal calcium overabsorption and hypercalciuria is unknown, but three hypotheses include: a primary overproduction of 1,25-dihydroxyvitamin $\mathrm{D}_{3}$ $\left(1,25(\mathrm{OH})_{2} \mathrm{D}_{3}\right)^{1}$ resulting from an abnormality in the control

Presented in part at the Annual Meeting of the Endocrine Society, Indianapolis, June 1987, and at the Annual Meeting of the American Society of Nephrology, Washington, DC, December 1987.

Address reprint requests to Dr. Bushinsky, Nephrology Section, Box 28, Pritzker School of Medicine, The University of Chicago, 5841 S. Maryland Avenue, Chicago, IL 60637.

Received for publication 25 January 1988 and in revised form 27 June 1988.

1. Abbreviations used in this paper: $\mathrm{Gt}$, tissue conductance; $\mathrm{HF}$, hypercalciuric female; HM, hypercalciuric male; $I_{s c}$, short circuit current;

J. Clin. Invest.

(C) The American Society for Clinical Investigation, Inc.

$0021-9738 / 88 / 11 / 1585 / 07 \quad \$ 2.00$

Volume 82, November 1988, 1585-1591 of $1,25(\mathrm{OH})_{2} \mathrm{D}_{3}$ biosynthesis; a primary increase in enterocyte calcium transport independent of $1,25(\mathrm{OH})_{2} \mathrm{D}_{3}$; and a primary renal tubular calcium transport defect or "renal leak" of calcium with compensatory increase in parathyroid hormone, $1,25(\mathrm{OH})_{2} \mathrm{D}_{3}$ and net intestinal calcium absorption $(17,18)$. Each of the possible mechanisms is supported by observations in patients (17-23).

In man it is difficult to separate the many factors, including dietary habits and genetic traits, which may contribute to the hypercalciuric syndrome. An animal model would be potentially valuable to test hypotheses regarding genetic and environmental components of hypercalciuria. Hypercalciuria occurs spontaneously among rats (24), and mating of hypercalciuric rats results in enrichment of hypercalciuria among offspring $(25,26)$. Our approach has been to establish a colony of genetically hypercalciuric rats through selective inbreeding and use them to explore the pathogenetic role of intestinal calcium absorption and $1,25(\mathrm{OH})_{2} \mathrm{D}_{3}$ in hypercalciuria. The present study describes genetic hypercalciuria in rats and the disturbances in mineral metabolism that may account for the hypercalciuria.

\section{Methods}

Establishment of genetic hypercalciuric rats. 20 male and 20 female adult Sprague-Dawley rats (Charles River Laboratories, Kingston, NY) were screened for hypercalciuria. The rats were placed in individual metabolic cages and allowed $5 \mathrm{~d}$ to adjust to the cage and diet. During this time, the animals were fed $13 \mathrm{~g} / \mathrm{d}$ of a diet containing $0.6 \% \mathrm{cal}$ cium, $0.65 \%$ phosphorus, $0.24 \%$ magnesium, $0.4 \%$ sodium, $0.43 \%$ chloride, and 2.2 IU vitamin $D_{3}$ per gram of food. Deionized distilled water was given ad lib. In previous studies, $5 \mathrm{~d}$ was sufficient to achieve stable values of fecal and urine calcium (27-32). Two successive 24-h urine collections in $0.25 \mathrm{ml} 12 \mathrm{~N} \mathrm{HCl}$ were then obtained on days 6 and 7 to measure the urine calcium excretion. The three male and three female rats with the greatest calcium excretion were used to breed the next generation. A similar protocol was used to select the two to three hypercalciuric males and three to four hypercalciuric females for inbreeding of subsequent generations.

Mineral balance techniques. The male and female fourth generation inbred rats and male and female control rats were kept in the metabolic cages, continued on the same amount of the same diet and a 6-d balance study was performed. The control rats were the same long established strain (Sprague-Dawley) obtained from the same supplier (as above) and were studied concurrently at the same age and weight as the inbred hypercalciuric rats. During all $6 \mathrm{~d}$ of the balance study complete individual 24-h urines were collected in $0.25 \mathrm{ml} 12 \mathrm{~N} \mathrm{HCl}$; complete individual 24-h feces were collected, and food and fluid intake were recorded (27-29). The collections for each day were analyzed individually, and the individual values were added to obtain the 6-d accumulated total. Net intestinal absorption was calculated by subtracting fecal excretion from the corresponding intake. Daily bal-

$J_{\text {ms }}$, mucosa-to-serosa flux; $J_{\text {net }}$, net calcium flux; $J_{\text {sm }}$, serosa-to-mucosa flux; NF, normocalciuric female; NM, normocalciuric male; $1,25(\mathrm{OH})_{2} \mathrm{D}_{3}, 1,25$-dihydroxyvitamin $\mathrm{D}_{3}$. 
ance was calculated by subtracting urine and fecal excretions from the intake. Rats that ate $<12 \mathrm{~g}$ of food or drank $<15 \mathrm{ml}$ of fluid on any day were eliminated from the study. On the morning of the seventh day of the balance study, after the final urine and fecal collections were completed, blood was obtained from the carotid artery of each rat under light ether anesthesia, and the duodenum was rapidly removed for transport studies. Serum was separated from cells within $30 \mathrm{~min}$ and either frozen at $-25^{\circ} \mathrm{C}$ or diluted for biochemical measurements. The two males and four females with the greatest calcium excretion were not sacrificed to allow for maintenance of the colony.

In vitro calcium transport. Adjacent segments from the first $2 \mathrm{~cm}$ distal to the common bile duct of the duodenum were rinsed with ice cold saline and mounted as the partition between two Lucite hemichambers with an exposed tissue area of $0.49 \mathrm{~cm}^{2}$. Mucosal and serosal surfaces were bathed in a bicarbonate buffered Krebs-Ringer solution $(\mathrm{pH}=7.4)$ containing, in $\mathrm{mM}: \mathrm{NaCl}, 120 ; \mathrm{NaHCO}_{3}, 25 ; \mathrm{KCl}, 5$; $\mathrm{CaCl}_{2}, 1.25 ; \mathrm{MgSO}_{4}, 1.2$; and D-glucose, 11. Reservoirs were gassed continuously with $\mathrm{O}_{2}: \mathrm{CO}_{2}, 95: 5$, to maintain $\mathrm{pH}$ at 7.4 and to provide adequate mixing. Unidirectional calcium fluxes were measured as previously described (33) using ${ }^{45} \mathrm{Ca}\left(\mathrm{as} \mathrm{CaCl}_{2}\right)$ as tracer. Steady-state fluxes of calcium from mucosa to serosa $\left(J_{\mathrm{ms}}\right)$ and serosa to mucosa $\left(J_{\mathrm{sm}}\right)$ were calculated by a computer program based upon the method of Schultz and Zalusky (34). Net calcium flux $\left(J_{\text {net }}\right)$ is the difference between $J_{\mathrm{ms}}$ and $J_{\mathrm{sm}}$, where positive values equal net absorption.

Spontaneous electrical gradients across the epithelium were neutralized by a continuous short-circuit current according to previously described methods $(35,36)$, except for brief periods of interruption to measure tissue potential differenee. Steady-state fluxes from each rat were used in the analysis only if conductance of the paired tissues agreed within $30 \%$.

Serum $1,25(\mathrm{OH})_{2} D_{3}$. Frozen $1.0-\mathrm{ml}$ aliquots from each rat were thawed at room temperature and equilibrated with $1,500 \mathrm{cpm}$ of $\left[{ }^{3} \mathrm{H}\right]$ $1,25(\mathrm{OH})_{2} \mathrm{D}_{3}(101 \mathrm{Ci} / \mathrm{mmol}$; Amersham Searle, Arlington Heights, IL) to monitor procedural losses. Extraction and separation of $1,25(\mathrm{OH})_{2} \mathrm{D}_{3}$ from serum lipids and other vitamin $\mathrm{D}$ metabolites was performed by the method of Reinhardt et al. (37) as previously described (38). $1,25(\mathrm{OH})_{2} \mathrm{D}_{3}$ content of each sample was quantified in triplicate using the calf thymus cytosol receptor assay $(37,38)$. Overall sample recovery was $54 \pm 2 \%$ (mean \pm SE for 40 samples). Assay sensitivity (least detectable level) was $0.6 \mathrm{pg}$ per assay tube. Samples were analyzed blind in two consecutive assays. Intra- and interassay coefficients of variation were 10 and $18 \%$, respectively.

Fecal extraction. Stool mineral was extracted by dissolving each 24-h fecal collection in $35 \%$ nitric acid and $35 \%$ perchloric acid (by volume) at $95^{\circ} \mathrm{C}$ for $7 \mathrm{~h}$. The solution was brought to total volume of $25 \mathrm{ml}$ with deionized water, and calcium, phosphorus, magnesium, sodium, and potassium were measured (27-29).

Chemical determinations. Total calcium and magnesium in serum, urine, and feces were measured by atomic absorption spectrometry (model Video 22; Instrumentation Laboratory, Andover, MA) using aqueous standards (27-32). Phosphorus in serum, urine, and feces were measured by AutoAnalyzer methods (model II; Technicon, Inc., Tarrytown, NY) (27-32). Sodium and potassium in the serum, urine, and feces were measured by flame photometry (model 443; Instrumentation Laboratory) as previously described (27-32).

Statistical analyses. Differences between groups were assessed using analysis of variance, regressions were calculated by least squares. All calculations used standard methods (BMDP; University of California at Los Angeles) written for a digital computer (PDP 11/44; Digital Equipment Corp., Maynard, MA). Mean values are \pm SE. Group differences with $P$ values $\leq 0.05$ are considered to be statistically significant; NS indicates nonsignificance.

\section{Results}

Hypercalciuria in the fourth generation. After inbreeding four generations of hypercalciuric rats, urine calcium excretion in
16 of 18 males $(89 \%)$ and 14 of 25 females (56\%) was two standard deviations above the mean of the control rats (mean $\pm 2 \mathrm{SD}$ of the concurrent screening values: for the control males, $0.96 \mathrm{mg} / 24 \mathrm{~h}$; for the control females, $1.18 \mathrm{mg} / 24 \mathrm{~h}$ ). These 16 hypercalciuric male (HM) and 14 hypercalciuric female (HF) rats were used for the balance studies and compared to 10 normocalciuric male (NM) and 10 normocalciuric female (NF) rats. No individual NM or NF rat had a urine calcium excretion $>2$ SD over the same sex mean.

Mineral balance. For each of the six 24-h urine collections, urine calcium excretion was greater in HM and HF rats compared with their sex-matched controls indicating that hypercalciuria was chronic and stable (Table I). The increased individual daily excretion resulted in a greater cumulative $6 \mathrm{~d}$ total calcium excretion in the hypercalciuric rats (Table II, Fig. 1). As we have reported previously NF excreted more calcium than NM (27), however, there was no difference in urine calcium excretion between HM and HF. Net intestinal calcium absorption was greater in HM and HF compared to their sexmatched controls. NM absorbed more dietary calcium than NF (27). In both HM and HF net intestinal calcium absorption exceeded urine calcium loss so that calcium balance was more positive in the hypercalciuric rats than in their respective-sex normocalciuric controls. NM were in greater positive calcium balance than NF (27). Net intestinal calcium absorption was correlated directly with urine calcium excretion in NM and HM $(r=0.647, n=25, P<0.001)$ but not with NF and $\mathrm{HF}(r=0.290, n=24, P=\mathrm{NS})$.

Urine phosphorus excretion was greater in HM than NM, however phosphorus excretion was not different in NF and HF (Table II). HM absorbed more phosphorus than NM, but phosphorus absorption was not different in HF and NF. Phosphorus balance was not different between HM and NM or between HF and NF; however, all males retained more phosphorus than all females. Urine magnesium excretion, absorption, and balance were not different between HM and NM or between HF and NF (Table II), although all males excreted, absorbed, and retained more magnesium than all females.

Sodium and potassium balances were positive in all animals, however hypercalciuric males and females were in less positive balance because urine excretions of sodium and potassium were greater than in sex-matched normocalciuric animals (Table III). Urine calcium excretion was significantly correlated with urine sodium excretion for all four groups of rats combined over the $6 \mathrm{~d}$ of balance $(r=0.727, n=49$, $P<0.001$, Fig. 2).

Table I. Daily Urine Calcium Excretion

\begin{tabular}{lcccc}
\hline & $\begin{array}{c}\text { NM } \\
10\end{array}$ & $\begin{array}{c}\text { HM } \\
16\end{array}$ & $\begin{array}{c}\text { NF } \\
10\end{array}$ & $\begin{array}{c}\text { HF } \\
14\end{array}$ \\
\hline Day 1 & $0.53 \pm 0.05$ & $1.80 \pm 0.18^{*}$ & $0.60 \pm 0.05^{\dagger}$ & $1.60 \pm 0.15^{* *}$ \\
Day 2 & $0.55 \pm 0.07$ & $1.93 \pm 0.21^{*}$ & $0.93 \pm 0.11^{\dagger}$ & $1.87 \pm 0.18^{* \ddagger}$ \\
Day 3 & $0.59 \pm 0.07$ & $2.26 \pm 0.19^{*}$ & $0.96 \pm 0.13^{* \dagger}$ & $1.56 \pm 0.14^{* *}$ \\
Day 4 & $0.87 \pm 0.14$ & $1.70 \pm 0.16^{*}$ & $0.87 \pm 0.07^{\dagger}$ & $1.73 \pm 0.17^{* *}$ \\
Day 5 & $0.65 \pm 0.05$ & $2.13 \pm 0.22^{*}$ & $0.70 \pm 0.06^{\dagger}$ & $2.17 \pm 0.25^{* \ddagger}$ \\
Day 6 & $0.72 \pm 0.08$ & $1.72 \pm 0.21^{*}$ & $0.79 \pm 0.09^{\dagger}$ & $1.94 \pm 0.18^{* *}$
\end{tabular}

Values are mean $\pm \mathrm{SE}$ in $\mathrm{mg} / 24 \mathrm{~h}$ for $n$ rats in each group. Urine was collected in $0.25 \mathrm{ml} 12 \mathrm{~N} \mathrm{HCl}$.

* Different from NM, $P<0.05 ;{ }^{\dagger}$ Different from HM, $P<0.05 ;{ }^{\ddagger}$ Different from NF, $P<0.05$. 
Table II. Calcium, Phosphorus, and Magnesium Balance

\begin{tabular}{|c|c|c|c|c|}
\hline & $\begin{array}{lc} & \mathrm{NM} \\
n & 10\end{array}$ & $\begin{array}{c}\text { HM } \\
16\end{array}$ & $\begin{array}{c}\text { NF } \\
10\end{array}$ & $\begin{array}{l}\text { HF } \\
14\end{array}$ \\
\hline \multicolumn{5}{|l|}{ Calcium } \\
\hline Intake & $468 \pm 0$ & $468 \pm 0$ & $468 \pm 0$ & $468 \pm 0$ \\
\hline Urine & $3.9 \pm 0.3$ & $11.5 \pm 1.0^{*}$ & $4.8 \pm 0.3^{* \sharp}$ & $10.9 \pm 0.6^{*}$ \\
\hline Fecal & $201 \pm 4$ & $166 \pm 5^{*}$ & $384 \pm 11^{\text {** }}$ & $353 \pm 10^{* \neq 5}$ \\
\hline Absorption & $267 \pm 4$ & $302 \pm 5^{*}$ & $84 \pm 11^{* \neq}$ & $115 \pm 10^{* * 5}$ \\
\hline Net balance & $263 \pm 4$ & $291 \pm 5^{*}$ & $79 \pm 11^{* *}$ & $104 \pm 10^{* \pm 5}$ \\
\hline \multicolumn{5}{|l|}{ Phosphorus } \\
\hline Intake & $507 \pm 0$ & $507 \pm 0$ & $507 \pm 0$ & $507 \pm 0$ \\
\hline Urine & $184 \pm 4$ & $206 \pm 5^{*}$ & $194 \pm 4$ & $203 \pm 1^{*}$ \\
\hline Fecal & $129 \pm 3$ & $115 \pm 3^{*}$ & $244 \pm 7 * t$ & $237 \pm 7^{* *}$ \\
\hline Absorption & $378 \pm 3$ & $392 \pm 3^{*}$ & $263 \pm 7^{* \ddagger}$ & $270 \pm 7^{\text {\#\# }}$ \\
\hline Net balance & $194 \pm 5$ & $186 \pm 4$ & $69 \pm 8^{* *}$ & $67 \pm 8^{* *}$ \\
\hline \multicolumn{5}{|l|}{ Magnesium } \\
\hline Intake & $187.2 \pm 0$ & $187.2 \pm 0$ & $187.2 \pm 0$ & $187.2 \pm 0$ \\
\hline Urine & $88 \pm 4$ & $87 \pm 2$ & $55 \pm 2^{* *}$ & $59 \pm 2^{* *}$ \\
\hline Fecal & $80 \pm 2$ & $76 \pm 1$ & $125 \pm 3^{* *}$ & $129 \pm 3^{* *}$ \\
\hline Absorption & $107 \pm 2$ & $111 \pm 1$ & $62 \pm 3^{* *}$ & $58 \pm 3^{* 1}$ \\
\hline Net balance & $19 \pm 3$ & $24 \pm 2$ & $7 \pm 3^{* *}$ & $0.6 \pm 2^{* *}$ \\
\hline
\end{tabular}

Values are mean $\pm \mathrm{SE}$ in $\mathrm{mg} / 6 \mathrm{~d}$ for $n$ rats in each group. Intake is cumulative intake of the ion over $6 \mathrm{~d}$. As all rats consumed the entire amount of food each day the SE for intake are all zero. Urine is the cumulative urinary excretion of the ion over $6 \mathrm{~d}$. Fecal is the cumulative fecal excretion of the ion over $6 \mathrm{~d}$. Net intestinal absorption was calculated by subtracting fecal excretion from the corresponding intake. Net balance is calculated by subtracting urine and fecal excretion from intake; the sum of $6 \mathrm{~d}$ is reported.

* Different from NM, $P<0.05 ;{ }^{\ddagger}$ Different from HM, $P<0.05 ;{ }^{8}$ Different from NF, $P<0.05$.

Intestinal calcium transport. Under steady-state conditions, a positive net calcium flux ( $J_{\mathrm{ms}}$ greater than $J_{\mathrm{sm}}$; net absorption) was present across duodenum in all groups (Table IV). HM tended to have higher $J_{\text {net }}$ than NM, and $J_{\text {net }}$ in HF was greater than in NF (Fig. 3). The increased Jnet in HF was
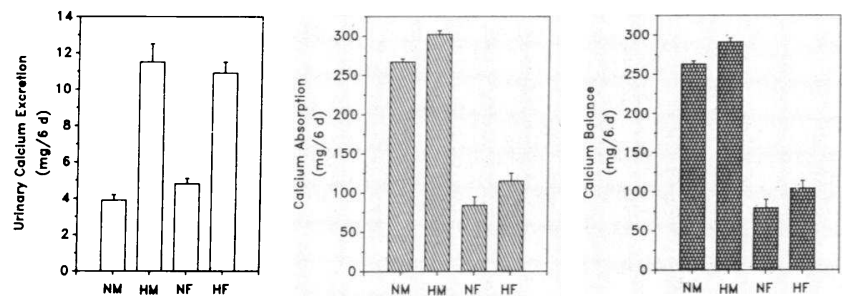

Figure 1., Urinary excretion, net intestinal absorption and net balance of calcium. Values are mean \pm SE. NM, normal male (10 rats); $\mathrm{HM}$, hypercalciuric male (16 rats); NF, normal female (10 rats); HF, hypercalciuric female (14 rats). Urinary excretion (clear bars) is the cumulative excretion of calcium during $6 \mathrm{~d}$. Net intestinal absorption (diagonal striped bars) is calculated by subtracting fecal excretion from the corresponding intake. Net balance (hatched bars) is calculated by subtracting urine and fecal excretion from intake; the sum of the $6 \mathrm{~d}$ is reported. Urine calcium excretion was greater in HM than NM and in HF than in NF (statistics as in Table II). NF excreted more calcium than NM, however, there was no difference between $\mathrm{HF}$ and HM. Calcium absorption was greater in HM than in $\mathrm{NM}$ and in $\mathrm{HF}$ than in NF even though serum $1,25(\mathrm{OH})_{2} \mathrm{D}_{3}$ was actually lower in HM than in NM and no different in HF and NF. NM absorbed more calcium than NF and HM more than HF. Net calcium balance was greater in HM than in NM and in HF than in NF. Net calcium balance was greater both in NM than in NF and in HM than in HF. Each rat consumed all food on all days so that calcium intake was identical in each group. due to a threefold increase in $J_{\mathrm{ms}}\left(87 \pm 21 \mathrm{vs} .31 \pm 4 \mathrm{nmol} / \mathrm{cm}^{2}\right.$ per $\mathrm{h}, P<0.001$ ), to levels equivalent to those observed in NM and HM. $J_{\mathrm{ms}}$ tended to be higher in HM than NM, but the wide range of values in $\mathrm{HM}$ prevented the differences from reaching significance. $J_{\mathrm{sm}}$ was also increased in HF, whereas the other three groups had comparable values of $J_{\mathrm{sm}}$.

HF and HM had lower tissue conductance $\left(G_{t}\right)$ than their normocalciuric cohorts, and HF had higher short circuit current $\left(I_{\mathrm{sc}}\right)$ than NF and all males (Table IV).

Serum chemistries. Despite the threefold higher duodenal calcium $J_{\mathrm{ms}}$ in $\mathrm{HF}$, serum $1,25(\mathrm{OH})_{2} \mathrm{D}_{3}$ levels were not different from NF (Table V). Mean calcium $J_{\mathrm{ms}}$ was not different between $\mathrm{HM}$ and $\mathrm{NM}$, but $\mathrm{HM}$ had serum $1,25(\mathrm{OH})_{2} \mathrm{D}_{3}$ concentrations one-half that of NM (Fig. 3). As we have reported previously NF had lower serum $1,25(\mathrm{OH})_{2} \mathrm{D}_{3}$ concentrations than NM (27). No difference in total serum calcium or magnesium concentrations was observed among the four groups (Table V). Serum phosphorus was lower in females compared to males. Females weighed more than males at sacrifice because males were studied first; however, there was no difference in the final weight, or weight at the initiation of the balance study between NM and HM or between NF and HF (Table V).

Correlation of absorption, $J_{\text {net }}$, and serum $1,25(\mathrm{OH})_{2} \mathrm{D}_{3}$. Net intestinal calcium absorption during the 6-d balance study was correlated directly with duodenal calcium $J_{\text {net }}$ in HM and HF $(r=0.456, n=19, P<0.04)$ and in NM and NF $(r=0.880, n=15, P<0.001)$. The two regressions were not different $(F$ ratio $=1.18, P=$ NS) and could be combined. The combined overall regression $(r=0.572, n=34, P<0.001)$ indicates the significant correlation between in vivo net intestinal calcium absorption and in vitro duodenal calcium net flux in all four groups of animals used in this experiment.

Net intestinal calcium absorption was correlated directly with serum $1,25(\mathrm{OH})_{2} \mathrm{D}_{3}$ in $\mathrm{NM}$ and $\mathrm{NF}(r=0.724, n=15, P$ $<0.001$ ); however, there was no correlation in $\mathrm{HM}$ and $\mathrm{HF}(r$ $=0.296, n=21, P=\mathrm{NS}$ ).

$J_{\text {net }}$ was correlated directly with serum $1,25(\mathrm{OH})_{2} \mathrm{D}_{3}$ in $\mathrm{NM}$ and NF $(r=0.789, n=12, P<0.001)$ and in HF and HM ( $r=0.500, n=17, P<0.03$ ). However, the regressions were different $(F$ ratio $=5.469, n=29, P<0.015$, Fig. 4$)$ due to a difference in slope. With increasing levels of serum $1,25(\mathrm{OH})_{2} \mathrm{D}_{3}$ there was a greater absorption of calcium by the hypercalciuric rats compared to the normocalciuric controls (Fig. 4).

\section{Discussion}

Hypercalciuria in our colony of genetic hypercalciuric rats is due to a primary intestinal overabsorption of dietary calcium. At comparable levels of serum $1,25(\mathrm{OH})_{2} \mathrm{D}_{3}$ the hypercalciuric rats have greater rates of net intestinal calcium absorption (Fig. 1) and more positive calcium balance (Fig. 1) than sexmatched normocalciuric animals. Circulating $1,25(\mathrm{OH})_{2} \mathrm{D}_{3}$ levels were lower in male hypercalciuric rats, and there was no difference in the female rats (Table V). Thus, there is no evidence from measurements of serum $1,25(\mathrm{OH})_{2} \mathrm{D}_{3}$ levels that the increased net calcium absorption in the hypercalciuric animals was driven by excess $1,25(\mathrm{OH})_{2} \mathrm{D}_{3}$. In addition, excess $1,25(\mathrm{OH})_{2} \mathrm{D}_{3}$ does not lead to increased calcium balance in rat (28) or man $(39,40)$. 
Table III. Sodium and Potassium Balance

\begin{tabular}{|c|c|c|c|c|}
\hline & NM & HM & NF & $\mathrm{HF}$ \\
\hline \multicolumn{5}{|l|}{ Sodium } \\
\hline Intake & $13.56 \pm 0$ & $13.56 \pm 0$ & $13.56 \pm 0$ & $13.56 \pm 0$ \\
\hline Urine & $9.70 \pm 0.2$ & $12.5 \pm 0.3^{*}$ & $10.6 \pm 0.2^{* \pm}$ & $12.1 \pm 0.2^{* \S}$ \\
\hline Fecal & $0.31 \pm 0.05$ & $0.22 \pm 0.03$ & $0.36 \pm 0.05^{\ddagger}$ & $0.42 \pm 0.03^{\ddagger}$ \\
\hline Net balance & $3.6 \pm 0.2$ & $0.8 \pm 0.3^{*}$ & $2.6 \pm 0.2^{* \ddagger}$ & $1.0 \pm 0.6^{* \S}$ \\
\hline \multicolumn{5}{|l|}{ Potassium } \\
\hline Intake & $7.98 \pm 0$ & $7.98 \pm 0$ & $7.98 \pm 0$ & $7.98 \pm 0$ \\
\hline Urine & $4.5 \pm 0.1$ & $6.0 \pm 0.2^{*}$ & $5.7 \pm 0.1^{*}$ & $6.9 \pm 0.2^{* \neq \S}$ \\
\hline Fecal & $0.43 \pm 0.03$ & $0.31 \pm 0.03^{*}$ & $0.44 \pm 0.04^{\ddagger}$ & $0.57 \pm 0.03^{* \neq \S}$ \\
\hline Net balance & $3.1 \pm 0.1$ & $1.7 \pm 0.2^{*}$ & $1.8 \pm 0.3^{*}$ & $0.5 \pm 0.2^{* \neq \S}$ \\
\hline
\end{tabular}

All values are mean $\pm \mathrm{SE}$ with units of meq/ $6 \mathrm{~d}$. Number of rats in each group, abbreviations, calculations, and statistics as in Table II.

Compared to their respective sex controls, both the hypercalciuric male and female rats had increased urinary sodium excretion, which was correlated directly with urinary calcium when all four groups of rats were combined (Fig. 2). Since calcium clearance is directly correlated with sodium clearance $(41,42)$ it is possible that the hypercalciuria in our inbred rats was secondary to a genetic increase in sodium clearance. A primary renal leak of calcium or sodium would be expected to cause negative or, at best, neutral balance (17). However, both male and female hypercalciuric rats are in more positive calcium balance than their sex-matched normocalciuric controls (Table II), thus eliminating a primary renal tubular defect in sodium or calcium transport as the sole cause of the hypercalciuria. In addition, sodium-induced hypercalciuria increases circulating $1,25(\mathrm{OH})_{2} \mathrm{D}_{3}$ levels (43); however, serum $1,25(\mathrm{OH})_{2} \mathrm{D}_{3}$ levels are not elevated in the hypercalciuric female rats, and are actually lower in the hypercalciuric male rats (Table $\mathrm{V}$ ). These observations strongly argue against the sodium-driven hypercalciuria hypothesis.

The increase in net intestinal calcium absorption determined by the balance studies in both the male and female

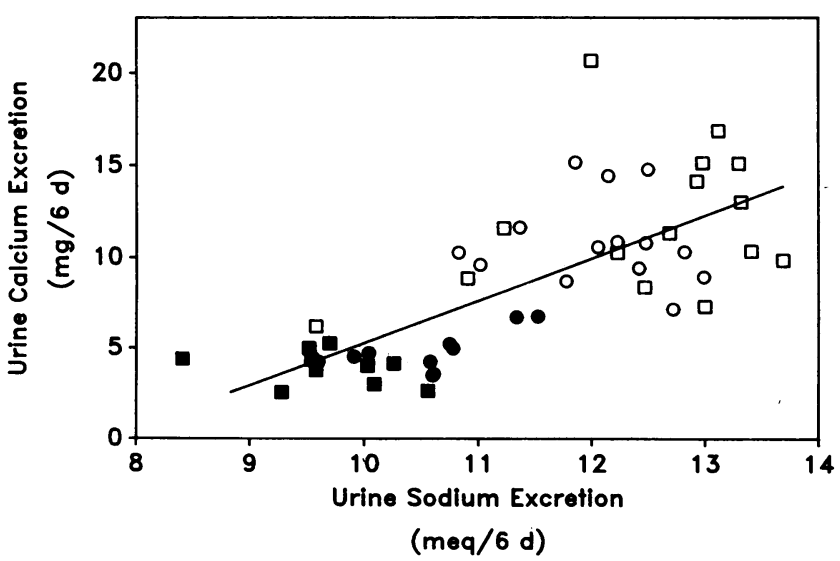

Figure 2. Urine calcium excretion ( $\mathrm{mg} / 6 \mathrm{~d})$ as a function of urine sodium excretion (meq/6 d) for hypercalciuric and normocalciuric male (open and closed squares, respectively) and female (open and closed circles, respectively) rats. For all rats combined urine calcium excretion was correlated with urine sodium excretion $(r=0.727$, $n=49, P<0.001$, solid line). hypercalciuric rats and the increase in duodenal calcium $J_{\text {net }}$ in vitro in the female hypercalciuric animals indicate that at least a portion of the positive calcium balance was the result of an increase in cellular active transport. $1,25(\mathrm{OH})_{2} \mathrm{D}_{3}$ is the major stimulus for calcium absorption, yet serum $1,25(\mathrm{OH})_{2} \mathrm{D}_{3}$ levels were not elevated commensurate with the rise in transport. In the normocalciuric rats there was a strong correlation between both $J_{\text {net }}$, and net intestinal calcium absorption, and the level of serum $1,25(\mathrm{OH})_{2} \mathrm{D}_{3}$; however, in the hypercalciuric rats the correlation between $J_{\text {net }}$ and $1,25(\mathrm{OH})_{2} \mathrm{D}_{3}$ was somewhat less strong and there was no correlation between net intestinal calcium absorption and $1,25(\mathrm{OH})_{2} \mathrm{D}_{3}$. Therefore, one expression of the inherited defect could be an altered responsiveness by enterocytes to $1,25(\mathrm{OH})_{2} \mathrm{D}_{3}$. For example an increase in vitamin $\mathrm{D}$ receptor occurs in enterocytes in response to $1,25(\mathrm{OH})_{2} \mathrm{D}_{3}(44)$, and a genetically mediated increase in receptor could increase calcium transport without a change in circulating $1,25(\mathrm{OH})_{2} \mathrm{D}_{3}$.

In this study, rats were selected for inbreeding solely by the presence of hypercalciuria. Hypercalciuria was found in $\sim 10 \%$ of an unselected population of rats fed normal laboratory chow (24). Breeding the most hypercalciuric males and females resulted in more frequent and more pronounced hypercalciuria among offspring. By the fourth generation hyper-

Table IV. In Vitro Calcium Active Transport across Duodenum

\begin{tabular}{llccc}
\hline & NM & HM & NF & HF \\
& $n 8$ & 13 & 7 & 10 \\
\hline$J_{\text {ms }}$ & $85 \pm 6$ & $126 \pm 21$ & $31 \pm 4^{* \ddagger}$ & $87 \pm 21^{\S}$ \\
$J_{\text {sm }}$ & $17 \pm 2$ & $20 \pm 3$ & $22 \pm 3$ & $41 \pm 6^{* \ddagger \S}$ \\
$J_{\text {net }}$ & $67 \pm 6$ & $106 \pm 22$ & $10 \pm 5^{* \neq}$ & $46 \pm 18^{\ddagger \S}$ \\
$I_{\text {sc }}$ & $67 \pm 11$ & $89 \pm 8$ & $50 \pm 4^{* \ddagger}$ & $151 \pm 14^{* \ddagger \S}$ \\
$G_{\mathrm{t}}$ & $26 \pm 2$ & $19 \pm 1^{*}$ & $24 \pm 2^{* \neq}$ & $13 \pm 1^{* \S}$
\end{tabular}

Values are mean $\pm \mathrm{SE}$ for $\boldsymbol{n}$ rats in each group. Fluxes are in nanomoles per square centimeter per hour: $J_{\mathrm{ms}}$, mucosal to serosal; $J_{\mathrm{sm}}$, serosal to mucosal; and $J_{\mathrm{ms}}-J_{\mathrm{sm}}=J_{\text {net }}$, where positive values indicate net absorption. $I_{\mathrm{sc}}$ is short circuit current in $\mu \mathrm{A} / \mathrm{cm}^{2} ; G_{\mathrm{t}}$ is tissue conductance in $\mathrm{mmhos} / \mathrm{cm}^{2}$.

* Different from NM, $P<0.05$.

‡ Different from HM, $P<0.05$.

$\S$ Different from NF, $P<0.05$. 


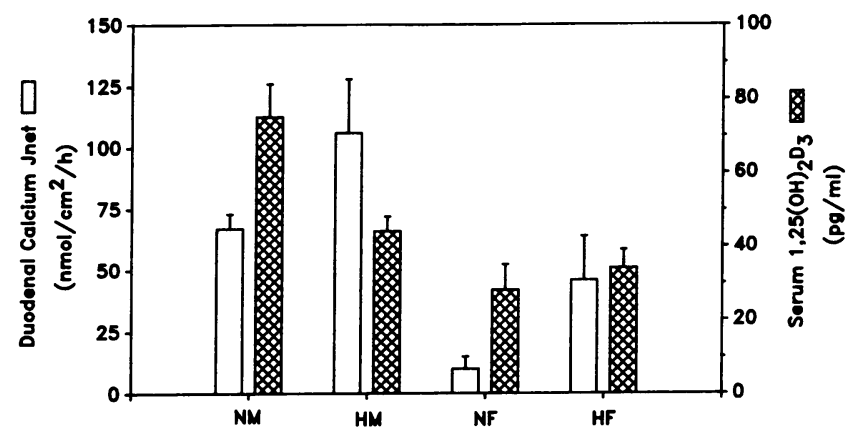

Figure 3. Duodenal calcium $J_{\text {net }}\left(\right.$ clear bars) and serum $1,25(\mathrm{OH})_{2} \mathrm{D}_{3}$ (hatched bars). Values are mean $\pm \mathrm{SE}$. Abbreviations and number of rats as in Fig. 1, statistics as in Table IV and V. HM tended to have a higher $J_{\text {net }}$ than NM and $J_{\text {net }}$ in HF was greater than NF. Serum $1,25(\mathrm{OH})_{2} \mathrm{D}_{3}$ was lower in $\mathrm{HM}$ than NM and no different between $\mathrm{HF}$ and NF. All females had lower serum $1,25(\mathrm{OH})_{2} \mathrm{D}_{3}$ than NM.

calciuria was present in $89 \%$ of male and $56 \%$ of female offspring. Genetic hypercalciuria in rats is not dissimilar to human idiopathic hypercalciuria, which may be familial and is thought to be genetic in origin (13-16). In man, hypercalciuria affects approximately $6 \%$ of children (45), a rate similar to the $5-10 \%$ prevalence reported among adults (46). In affected families of stone-formers with idiopathic hypercalciuria, $>40 \%$ of first degree relatives of proposti have hypercalciuria (14). These observations plus the horizontal and vertical patterns of occurrences of hypercalciuria in families support the hypothesis that idiopathic hypercalciuria is a genetic disorder. Environmental factors, such as habitual food intake, are difficult to control in man and may influence the clinical expression of a polygenetic disorder. However, variation in dietary intake cannot account for the hypercalciuria we observed in rats, as diet composition and amount were carefully controlled.

We have previously reported that serum $1,25(\mathrm{OH})_{2} \mathrm{D}_{3}$ is elevated in male rats, that males have less urinary calcium, absorb more dietary calcium, and are in greater calcium balance than female rats (27). Since male rats grow faster than females, we postulated that the elevated $1,25(\mathrm{OH})_{2} \mathrm{D}_{3}$ and decreased calcium excretion in males appears to be of biologic

Table V. Serum Values, Urine Volumes, and Final Weights

\begin{tabular}{lcccc}
\hline & NM & HM & NF & HF \\
& $n 8$ & 13 & 7 & 10 \\
\hline $1,25(\mathrm{OH})_{2} \mathrm{D}_{3}(\mathrm{pg} / \mathrm{ml})$ & $75 \pm 9$ & $44 \pm 4^{*}$ & $28 \pm 7^{*}$ & $34 \pm 5^{*}$ \\
Calcium $(m g / d l)$ & $11.1 \pm 0.3$ & $11.3 \pm 0.2$ & $10.8 \pm 0.1$ & $11.1 \pm 0.1$ \\
Phosphorus $(m g / d l)$ & $11.1 \pm 0.3$ & $10.5 \pm 0.4$ & $8.9 \pm 0.5^{* \ddagger}$ & $8.5 \pm 0.4^{* \ddagger}$ \\
Magnesium $(m g / d l)$ & $3.0 \pm 0.1$ & $2.9 \pm 0.1$ & $2.9 \pm 0.1$ & $2.7 \pm 0.1$ \\
Urine volume $(m l)$ & $10 \pm 1$ & $17 \pm 2^{*}$ & $9 \pm 1^{\ddagger}$ & $14 \pm 2^{\S}$ \\
Final weight $(g)$ & $210 \pm 3$ & $217 \pm 2$ & $245 \pm 3^{* \ddagger}$ & $233 \pm 7^{* \ddagger}$ \\
& & & & \\
\hline
\end{tabular}

Values are mean \pm SE for $n$ rats in each group. Calcium, phosphorus and magnesium refer to serum measurements; urine volume, $6 \mathrm{~d}$ mean urine volume; final weights, rat weight at sacrifice before blood drawing.

* Different from NM, $P<0.05$; ${ }^{\ddagger}$ Different from HM, $P<0.05$;

${ }^{8}$ Different from NF, $P<0.05$.

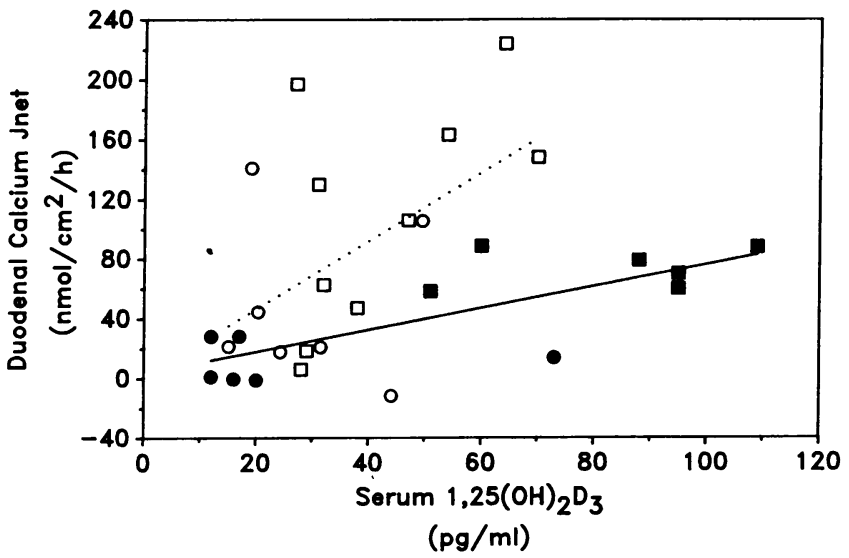

Figure 4. Duodenal calcium $J_{\text {net }}$ as a function of serum $1,25(\mathrm{OH})_{2} \mathrm{D}_{3}$ for hypercalciuric and normocalciuric male (open and closed squares, respectively) and female (open and closed circles, respectively) rats. $J_{\text {net }}$ and serum $1,25(\mathrm{OH})_{2} \mathrm{D}_{3}$ were correlated for male and female normocalciuric rats $\left(r=0.789, n=12, P<0.001\right.$, solid line, $J_{\text {net }}$ $=0.75\left(\right.$ serum $\left.\left.1,25(\mathrm{OH})_{2} \mathrm{D}_{3}\right)+3.18\right)$ and hypercalciuric rats $\left(r=0.500, n=17, P<0.03\right.$, dotted line, $J_{\text {net }}=2.28$ (serum $\left.\left.1,25(\mathrm{OH})_{2} \mathrm{D}_{3}\right)+1.00\right)$; the regressions were different $(F$ ratio $=5.469, P<0.015$ ).

significance and may help to satisfy a greater growth-related need for mineral (27). The elevated serum $1,25(\mathrm{OH})_{2} \mathrm{D}_{3}$, calcium absorption and calcium balance, and the decreased urinary calcium excretion in the normal males compared to the normal females in this study directly confirms our prior report (27). That only calcium and not phosphorus, magnesium, sodium, or potassium balance was increased in both the male and female hypercalciuric rats compared to their sex matched controls argues against errors in our balance methodology, which we have used to detect differences in calcium absorption, excretion and retention of a similar magnitude in rats in the past (27-29).

It is unclear if the increased net intestinal absorption in the hypercalciuric male and female rats is specific for calcium. There is no increase in magnesium absorption in either sex of hypercalciuric rats, and phosphorus absorption is not increased in the females. Additional balance and transport studies will be necessary to further define the extent of the abnormality in intestinal ion absorption.

The primary intestinal calcium overabsorption in the genetic hypercalciuric rats may be analogous to patients with absorptive idiopathic hypercalciuria who have increased intestinal calcium absorption with normal or slightly elevated $1,25(\mathrm{OH})_{2} \mathrm{D}_{3}$ serum levels $(7,12)$. Increased serum $1,25(\mathrm{OH})_{2} \mathrm{D}_{3}$ has been demonstrated in some patients with idiopathic hypercalciuria $(20,47)$, so absorptive hypercalciuria may be polygenic.

In the vast majority of patients with idiopathic hypercalciuria serum parathyroid hormone and urinary cAMP are normal $(7,9,18,20,22)$, thus we did not measure them in this study. In addition, in the rat we have never found either assay sensitive enough to demonstrate differences between groups except when extreme measures, such as a very low calcium diet $(<0.002 \%)$ are utilized $(27-30)$.

Micropuncture studies performed on female Wistar hypercalciuric rats revealed a defect in calcium reabsorption along 
the superficial late proximal tubule that was no longer present in the superficial early or late distal tubule (25). The increased calcium excretion in these rats was thought to be a function of diminished calcium reabsorption in the deep (inaccessible to micropuncture) nephrons (25). The decreased renal tubular reabsorption of calcium was supported by persistent hypercalciuria in vitamin D-deficient animals whose serum $1,25(\mathrm{OH})_{2} \mathrm{D}_{3}$ and intestinal calcium transport rates were markedly reduced and were comparable to normocalciuric controls (26). However, serum calcium did not fall in the hypercalciuric rats after an overnight fast, arguing against the hypothesis of decreased renal tubular calcium reabsorption. The hypercalciuric Wistar rats differ from our hypercalciuric animals in several ways. We screened for hypercalciuria while rats were consuming a diet adequate in calcium $(0.6 \%)$, whereas their rats were screened on a very low calcium diet ( $\leq \mathbf{0 . 0 3 \%}$ ), which would exclude animals who had a primary increase in intestinal calcium absorption. Our animals were in more positive calcium balance than the normocalciuric controls, whereas they found equivalent calcium balance in hyperand normocalciuric animals on low calcium diet in the vitamin D-deprived and repleted states (26). Also, serum $1,25(\mathrm{OH})_{2} \mathrm{D}_{3}$ levels in our hypercalciuric animals were equivalent (females) or lower (males) than controls, not higher as they report. The breeding experiments reported in the present study and those described previously $(25,26)$ appear to have resulted in different mechanisms of hypercalciuria through selection of different defects in calcium metabolism.

Over $99 \%$ of the total body calcium and a substantial amount of body sodium and potassium are localized within the bone mineral (48). Compared to sex-matched controls the increased retention of calcium and decreased retention of both sodium and potassium in the male and female hypercalciuric rats suggest that calcium may substitute for potassium and/or sodium in the bone mineral (49). Further studies, perhaps using the scanning ion microprobe to determine the surface ionic composition of bone, will be necessary to determine if there are abnormalities in the bone in the hypercalciuric rats (49).

Absorptive hypercalciuria has been described in one family with a pattern suggestive of a dominant mode of inheritance through four generations (14). The similarity between these familial forms of idiopathic hypercalciuria and genetic hypercalciuric animals suggests that insights into pathogenetic mechanisms can be tested in future generations of rats.

\section{Acknowledgments}

The authors wish to thank Vrishali Tembe, Carol Nalbantian-Brandt, Melissa Tanklefsky, and R. Ben Johnston for their expert technical assistance.

The studies were supported by program project grant PO1 33949 from the National Institutes of Health.

\section{References}

1. Pak, C. Y. C., O. Waters, L. Arnold, K. Holt, C. Cox, and D. Barilla. 1977. Mechanism for calcium urolithiasis among patients with hyperuricosuria. Supersaturation of urine with respect to monosodium urate. J. Clin. Invest. 59:426-431.

2. Weber, D. V., F. L. Coe, J. H. Parks, M. S. L. Dunn, and V. Tembe. 1979. Urinary saturation measurements in calcium nephrolithiasis. Ann. Intern. Med. 90:180-184.
3. Barilla, D. E., R. Tolentino, R. A. Kaplan, and C. Y. C. Pak. 1978. Selective effects of thiazide on intestinal absorption of calcium in absorptive and renal hypercalciurias. Metab. Clin. Exp. 27:125-131.

4. Birge, S. J., W. A. Peck, M. Berman, and G. D. Whedon. 1969. Study of calcium absorption in man. A kinetic analysis and physiologic model. J. Clin. Invest. 48:1705-1713.

5. Caniggia, A., C. Gennari, and L. Cesari. 1965. Intestinal absorption of ${ }^{45} \mathrm{Ca}$ in stone-forming patients. Br. Med. J. 1:427-429.

6. Ehrig, U., J. E. Harrison, and D. R. Wilson. 1974. Effect of long-term thiazide therapy on intestinal calcium absorption in patients with recurrent renal calculi. Metab. Clin. Exp. 23:139-149.

7. Kaplan, R. A., M. R. Haussler, L. J. Deftos, H. Bone, and C. Y. C. Pak. 1977. The role of 1-alpha,25-dihydroxyvitamin D in the mediation of intestinal hyperabsorption of calcium in primary hyperparathyroidism and absorptive hypercalciuria. J. Clin. Invest. 59:756760.

8. Pak, C. Y. C., D. A. East, L. J. Sanzenbacher, C. S. Delea, and F. C. Bartter. 1972. Gastrointestinal calcium absorption in nephrolithiasis. J. Clin. Endocrinol. Metab. 35:261-270.

9. Pak, C. Y. C., M. Ohata, E. C. Lawrence, and W. Snyder. 1974. The hypercalciurias. Causes, parathyroid functions, and diagnostic criteria. J. Clin. Invest. 54:387-400.

10. Shen, F. H., D. J. Baylink, R. L. Nielsen, D. J. Sherrard, J. L. Ivey, and M. R. Haussler. 1977. Increased serum 1,25-dihydroxyvitamin D in idiopathic hypercalciuria. J. Lab. Clin. Med. 90:955-962.

11. Wills, M. R., E. Zisman, J. Wortsman, R. G. Evans, C. Y. C. Pak, and F. C. Bartter. 1970. The measurement of intestinal calcium absorption by external radioisotope counting: application to study of nephrolithiasis. Clin. Sci. 39:95-106.

12. Zerwekh, J. E., and C. Y. C. Pak. 1980. Selective effects of thiazide therapy on serum 1 alpha, 25-dihydroxyvitamin $D$ and intestinal calcium absorption in renal and absorptive hypercalciurias. Metab. Clin. Exp. 29:13-17.

13. Pak, C. Y. C., J. McGuire, R. Peterson, F. Britton, and M. J. Harrod. 1981. Familial absorptive hypercalciuria in a large kindred. $J$. Urol. 126:717-719.

14. Coe, F. L., J. H. Parks, and E. S. Moore. 1979. Familial idiopathic hypercalciuria. N. Engl. J. Med. 300:337-340.

15. Aladjem, M., M. Modan, A. Lusky, R. Georgi, S. Orda, A. Eshkol, D. Lotan, and H. Boichis. 1983. Idiopathic hypercalciuria: a familial generalized renal hyperexcretory state. Kidney Int. 24:549554.

16. Mehes, K., and Z. S. Szelid. 1980. Autosomal dominant inheritance of hypercalciuria. Eur. J. Pediatr. 133:239-242.

17. Coe, F. L., and D. A. Bushinsky. 1984. Pathophysiology of hypercalciuria. Am. J. Physiol. 247 (Renal Fluid Electrolyte Physiol. 16):F1-F13.

18. Coe, F. L., and M. J. Favus. 1986. Disorders of stone formation. In The Kidney. B. M. Brenner and F. C. Rector, Jr., editors. W. B. Saunders \& Co., Philadelphia. 1403-1442.

19. Sutton, R. A. L., and V. R. Walker. 1980. Responses to hydrochlorothiazide and acetazolamide in patients with calcium stones. Evidence suggesting a defect in renal tubular function. N. Engl. J. Med. 302:709-713.

20. Broadus, A. E., K. L. Isogna, R. Lang, A. F. Ellison, and B. E. Dreyer. 1984. Evidence for disordered control of 1,25-dihydroxyvitamin D production in absorptive hypercalciuria. N. Engl. J. Med. 311:73-80.

21. Broadus, A. E., M. Dominguez, and F. C. Bartter. 1978. Pathophysiological studies in idiopathic hypercalciuria: use of an oral calcium tolerance test to characterize distinctive hypercalciuric subgroups. J. Clin. Endocrinol. Metab. 47:751-760.

22. Pak, C. Y. C., R. Kaplan, H. Bone, J. Townsend, and $O$. Waters. 1975. A simple test for the diagnosis of absorptive, resorptive and renal hypercalciurias. N. Engl. J. Med. 292:497-500.

23. Coe, F. L., M. J. Favus, T. Crockett, A. L. Strauss, J. H. Parks, A. Porat, C. L. Gantt, and L. M. Sherwood. 1982. Effects of low calcium diet on urine calcium excretion, parathyroid function and 
serum $1,25-(\mathrm{OH})_{2} \mathrm{D}_{3}$ levels in patients with idiopathic hypercalciuria and in normal subjects. Am. J. Med. 72:25-32.

24. Favus, M. J., and F. L. Coe. 1979. Evidence for spontaneous hypercalciuria in the rat. Miner. Electrolyte Metab. 2:150-154.

25. Lau, K., and B. K. Eby. 1982. Tubular mechanism for the spontaneous hypercalciuria in laboratory rat. J. Clin. Invest. 70:835844.

26. Lau, K., D. Thomas, C. Langman, and B. Eby. 1985. Pathophysiology of spontaneous hypercalciuria in laboratory rats. Role of deranged vitamin D metabolism. J. Clin. Invest. 76:420-425.

27. Bushinsky, D. A., M. J. Favus, and F. L. Coe. 1984. Elevated $1,25(\mathrm{OH})_{2} \mathrm{D}_{3}$, intestinal absorption, and renal mineral conservation in male rats. Am. J. Physiol. 246 (Renal Fluid Electrolyte Physiol. 15):F140-F145.

28. Bushinsky, D. A., M. J. Favus, and F. L. Coe. 1984. Mechanism of chronic hypocalciuria with chlorthalidone: reduced calcium absorption. Am. J. Physiol. 247 (Renal Fluid Electrolyte Physiol. 16):F746-F752.

29. Bushinsky, D. A., M. J. Favus, C. Langman, and F. L. Coe. 1986. Mechanism of chronic hypercalciuria with furosemide: increased calcium absorption. Am. J. Physiol. 251 (Renal Fluid Electrolyte Physiol. 20):F17-F24.

30. Bushinsky, D. A., M. J. Favus, A. B. Schneider, P. K. Sen, L. M. Sherwood, and F. L. Coe. 1982. Effects of metabolic acidosis on PTH and $1,25(\mathrm{OH})_{2} \mathrm{D}_{3}$ response to low calcium diet. Am. J. Physiol. 243 (Renal Fluid Electrolyte Physiol. 12):F570-F575.

31. Bushinsky, D. A., G. Riera, M. J. Favus, and F. L. Coe. 1985. Response of serum $1,25(\mathrm{OH})_{2} \mathrm{D}_{3}$ to variation of ionized calcium during chronic acidosis. Am. J. Physiol. 249 (Renal Fluid Electrolyte Physiol. 18):F361-F365.

32. Bushinsky, D. A., G. Riera, M. J. Favus, and F. L. Coe. 1985. Evidence that blood ionized calcium can regulate serum $1,25(\mathrm{OH})_{2} \mathrm{D}_{3}$ independently of parathyroid hormone and phosphorus in the rat. $J$. Clin. Invest. 76:1599-1604.

33. Favus, M. J., S. C. Kathpalia, F. L. Coe, and A. E. Mond. 1980. Effects of diet calcium and 1,25-dihydroxyvitamin $\mathrm{D}_{3}$ on colon calcium active transport. Am. J. Physiol. 238 (Gastrointest. Liver Physiol. 1):G75-G78.

34. Schultz, S. G., and R. Zalusky. 1964. Ion transport in isolated rabbit ileum. I. Short-circuit current and Na fluxes. J. Gen. Physiol. 47:567-584.

35. Favus, M. J., M. W. Walling, and D. V. Kimberg. 1974. Effects of dietary calcium restriction and chronic thyroparathyroidectomy on the metabolism of $\left[{ }^{3} \mathrm{H}\right] 25$-hydroxyvitamin $\mathrm{D}_{3}$ and the active transport of calcium by rat intestine. J. Clin. Invest. 53:1139-1148.

36. Field, M., D. Fromm, and I. McColl. 1971. Ion transport in rabbit ileal mucosa. I. $\mathrm{Na}$ and $\mathrm{Cl}$ fluxes and short-circuit current. Am. J. Physiol. 220:1388-1396.

37. Reinhardt, T. A., R. L. Horst, J. W. Orf, and B. W. Hollis. 1984. A microassay for 1,25-dihydroxyvitamin $\mathrm{D}$ not requiring high performance liquid chromatography: application to clinical studies. J. Clin. Endocrinol. Metab. 58:91-98.

38. Favus, M. J., and C. B. Langman. 1986. Evidence for calcium dependent control of 1,25-dihydroxyvitamin $\mathrm{D}_{3}$ production by rat kidney proximal tubules. J. Biol. Chem. 261:11224-11229.

39. Maierhofer, W. J., R. W. Gray, H. S. Cheung, and J. Lemann, Jr. 1983. Bone resorption stimulated by elevated serum $1,25-(\mathrm{OH})_{2^{-}}$ vitamin D concentrations in healthy men. Kidney Int. 24:555-560.

40. Lemann, J., Jr., R. W. Gray, W. J. Maierhofer, and H. S. Cheung. 1985. Hydrochlorothiazide inhibits bone resorption in men despite experimentally elevated serum 1,25-dihydroxyvitamin D concentrations. Kidney Int. 28:951-958.

41. Walser, M. 1961. Calcium clearance as a function of sodium clearance in the dog. Am. J. Physiol. 200:1099-1104.

42. Massry, S. G., J. W. Coburn, L. W. Chapman, and C. R. Kleeman. 1967. Effect of $\mathrm{NaCl}$ infusion on urinary $\mathrm{Ca}^{++}$and $\mathrm{Mg}^{++}$ during reduction in their filtered loads. Am. J. Physiol. 213:12181224.

43. Breslau, N. A., J. L. McGuire, J. E. Zerwekh, and C. Y. C. Pak. 1982. The role of dietary sodium on renal excretion and intestinal absorption of calcium and on vitamin D metabolism. J. Clin. Endocrinol. Metab. 55:369-373.

44. Favus, M. J., D. J. Mangelsdorf, V. Tembe, B. J. Coe, and M. R. Haussler. 1988. Evidence for in vivo up-regulation of the intestinal vitamin D receptor during dietary calcium restriction in the rat. $J$. Clin. Invest. 82:218-224.

45. Moore, E., F. L. Coe, B. McMann, and M. Favus. 1978. Idiopathic hypercalciuria in children: Prevalence and metabolic characteristics. J. Pediatr. 92:906-910.

46. Hodgkinson, A., and L. N. Pyrah. 1958. The urinary excretion of calcium and inorganic phosphate in 344 patients with calcium stone of renal origin. Br. J. Surg. 46:10-18.

47. Insogna, K. L., A. E. Broadus, B. E. Dreyer, A. F. Ellison, and J. M. Gertner. 1985. Elevated production rate of 1,25-dihydroxyvitamin D in patients with absorptive hypercalciuria. J. Clin. Endocrinol. Metab. 61:490-495.

48. Widdowson, E. M., R. A. McCance, and C. M. Spray. 1951. The chemical composition of the human body. Clin. Sci. 10:113-125.

49. Bushinsky, D. A., R. Levi-Setti, and F. L. Coe. 1986. Ion microprobe determination of bone surface elements: effects of reduced medium pH. Am. J. Physiol. 250 (Renal Fluid Electrolyte Physiol. 19):F1090-F1097. 